\title{
Ambiguous genitalia secondary to a Bartholin's cyst in a virilized newborn girl with maternal hyperandrogenemia
}

\author{
Swati Dave-Sharma, Christian Castillo, Yolanda Cosme, \\ Alberto Mendoza, Evelyn Erickson
}

\begin{abstract}
Introduction: Bartholin's gland cysts are rare in neonates. It is a cystic enlargement of the gland from a blockage of one of the Bartholin's ducts. The duct obstruction could be a result of a genital infection, inflammation or thickened mucus. It is imperative to keep in mind that the presence of a cyst in the genital area can present as ambiguous genitalia requiring careful management and follow-up. Congenital adrenal hyperplasia needs to be ruled out in females presenting with ambiguous genitalia. Case Report: We report a case of a full term newborn from a 28 years old G2P2 mother who presented with ambiguous genitalia. In the delivery room, the physical examination revealed clitoromegaly with a phallus measuring $2.5 \times 1 \mathrm{~cm}$ and otherwise normal examination. A bedside transillumination test was positive, indicative of a cyst in the clitoral area. The extensive endocrinological investigations revealed maternal and neontal hyperandrogenemia, 46XX chromosome and ultrasound evidence of presence of normal female internal genitalia. Clitoral enlargement showed spontaneous regression during the subsequent outpatient examinations. Surgery was performed at one
\end{abstract}

Swati Dave-Sharma1, Christian Castillo², Yolanda Cosme², Alberto Mendoza², Evelyn Erickson²

Affiliations: ${ }^{1} \mathrm{MD}$, Pediatric Endocrinology Division, Department of Pediatrics, Lincoln Medical \& Mental Health Center, Bronx, NY, United States; ${ }^{2}$ Department of Pediatrics, Lincoln Medical and Mental Health Center, Bronx, New York, USA

Corresponding Author: Swati Dave-Sharma, MD, 234 East 149th Street, 4-20, Bronx, NY, USA. 10451; Ph: 718-5795000; Fax: 718-579-4700; Email: daveshas@nychhc.org

Received: 29 October 2011

Accepted: 30 March 2012

Published: 01 April 2013 year of age for excision of the cyst. The pathology report of the surgical tissue at the time was reported as a Bartholin's cyst. Conclusion: Bartholin's cysts can be responsible for the presentation of ambiguous genitalia in a newborn girl with hyperandrogenemia. A multidisciplinary approach is necessary for diagnosis and management of the cyst, and to rule out significant conditions like congenital adrenal hyperplasia.

Keywords: Ambiguous Genitalia, Bartholin's cyst, Virilization, Hyperandrogenemia

$* * * * * * * * *$

Dave-Sharma S, Castillo C, Cosme Y, Mendoza A, Erickson E. Ambiguous genitalia secondary to a Bartholin's cyst in a virilized newborn girl with maternal hyperandrogenemia. International Journal of Case Reports and Images 2013;4(4):236-240.

$* * * * * * * * *$

doi:10.5348/ijcri-2013-04-302-CR-11

\section{INTRODUCTION}

Bartholin's gland cysts are rare in neonates [1]. Embryologically, they are outgrowths of the urogenital sinus, homologous to the bulbourethral glands in the male. The urogenital sinus comes from the cloaca and develops into the bladder, urethral glands, paraurethral glands, vagina, vestibular glands, Bartholin's glands, and hymen $[2,3]$. The function of these glands is to secrete mucus to lubricate the vagina. A Bartholin's gland cyst is a cystic enlargement of the gland from a blockage of one of the Bartholin's ducts. The duct obstruction could be a result of a genital infection, inflammation or thickened mucus. A painless mass in the vulva is the most common presenting sign. 
Recurrent Bartholin's gland abscesses can be treated by surgical excision of the gland and duct [1].

Virilization of urogenital sinus is the known cause of ambiguous genitalia in 46XX females with congenital adrenal hyperplasia (CAH). The degree of exposure to androgens determines the degree of urogenital virilization. Females can be born with mild clitoromegaly to male type penile urethra in patients with $\mathrm{CAH}$ [4].

Possible causes of maternal hyperandrogenemia causing virilization in both the mother and the newborn are polycystic ovarian syndrome, hyper-reactio luteinalis and maternal pregnancy luteoma. Luteomas are usually asymptomatic benign hyperplastic ovarian lesions of pregnancy that secrete androgens in $25 \%$ of cases [5]. A luteoma of pregnancy is reported to be the most common cause of maternal virilization during pregnancy. They are hypothesized to either arise from luteinized stromal cells responding atypically to hCG stimulation, or to be luteinized theca/granulosa cells. Pregnancy luteomas have been reported to undergo spontaneous postpartum regression at approximately three months after delivery.

\section{CASE REPORT}

A full-term newborn weighing $3.5 \mathrm{~kg}$ was born from a 28-year-old G2P2 mother by a normal spontaneous vaginal delivery without any complications. The prenatal course was uneventful, and the family medical history was unremarkable, including the mother's first born who was a healthy boy. There was no history of alcohol, smoking or any medication during the mother's pregnancy. The fetal ultrasound was normal.

In the delivery room, the physical examination revealed a newborn with ambiguous genitalia. A phallus was observed measuring $2.5 \times 1 \mathrm{~cm}$. There were absent gonads in the urogenital folds and the normal appearance of a vaginal introitus (Figures 1-3). Initial vital signs showed normal heart rate $145 / \mathrm{min}$, respiratory rate $52 / \mathrm{min}$ and blood pressure $89 / 48$ $\mathrm{mmHg}$. No other abnormalities were noted. The patient started feeding well and the nurses reported meconium passage four hours after birth and normal urine. An initial metabolic profile included serum sodium 142 $\mathrm{mmol} / \mathrm{L}$ (normal limits $137-147 \mathrm{mmol} / \mathrm{L}$ ), potassium $5.6 \mathrm{mmol} / \mathrm{L}$ (normal limits $3.6-5.2 \mathrm{mmol} / \mathrm{L}$ ), and $\mathrm{CO}_{2}$ $23 \mathrm{mmol} / \mathrm{L}$ (normal limits $22-32 \mathrm{mmol} / \mathrm{L}$ ).

The endocrinologist was consulted who requested 17-hydroxyprogesterone, testosterone, estradiol, a karyotype and a pelvic ultrasound to evaluate the type of internal genitalia. A chromosomal analysis revealed a 46XX female karyotype. A pelvic ultrasound showed normal uterus and ovaries. The urology service was consulted and reported the findings of female type genitals with a normal vaginal opening, an enlarged clitoris with a small opening at the base of the clitoris with a white milky discharge expressed when pressure was applied to it, a thickened labia, and a vagina and urethra in the normal anatomical position. Gender assignment was made as female. The results of the testosterone and estradiol levels were reported high for the patient's age and gender. Her initial testosterone level was $98 \mathrm{ng} / \mathrm{dL}$ (normal limits <24 ng/dL in newborn 1-10 days of age) and estradiol levels were 137 $\mathrm{pg} / \mathrm{dL}$ (normal limits $<16 \mathrm{pg} / \mathrm{mL}$ for pre-pubertal females). The newborn screening results were reported to be within normal limit.

While interviewing the mother in the newborn nursery, we noticed that the mother had hirsutism evident on the neck and face (Figure 4). She denied use of any hormonal treatment during pregnancy. As a result, blood tests were requested for the mother, which resulted in normal FSH and LH but high testosterone level of $166 \mathrm{ng} / \mathrm{dL}$ (normal limits 15-90 ng/dL).

A follow-up examination of the newborn, two weeks later, in an outpatient clinic showed a decrease in the size of the clitoris secondary to a partial regression of a cyst (Figure 5). At three months of age, her testosterone levels decreased to $40.13 \mathrm{ng} / \mathrm{dL}$ (normal limits for $1-3$ month old females $<17 \mathrm{ng} / \mathrm{dL}$ ). Maternal laboratory tests performed three months postpartum resulted in normal LH, FSH and testosterone levels (testosterone $37 \mathrm{ng} / \mathrm{dL}$ ).

Subsequently, at six months of age the testosterone was suppressed to $<10 \mathrm{ng} / \mathrm{dL}$ (normal limits $<13$ $\mathrm{ng} / \mathrm{dL}$ ). The outpatient examination by urologist was positive for the clitoris of the infant as enlarged and approximately $2.5 \mathrm{~cm}$ with a yellowish discharge. As a result, a marsupialization was performed at one year of age. The pathology report of the surgical tissue at the time was reported as a Bartholin's cyst.

Retrospectively, the diagnosis of a luteoma of pregnancy was considered due to the clinical presentation of the mother and her virilized infant, especially due to the normalizing of the mother's hormonal levels three months postpartum without any intervention.

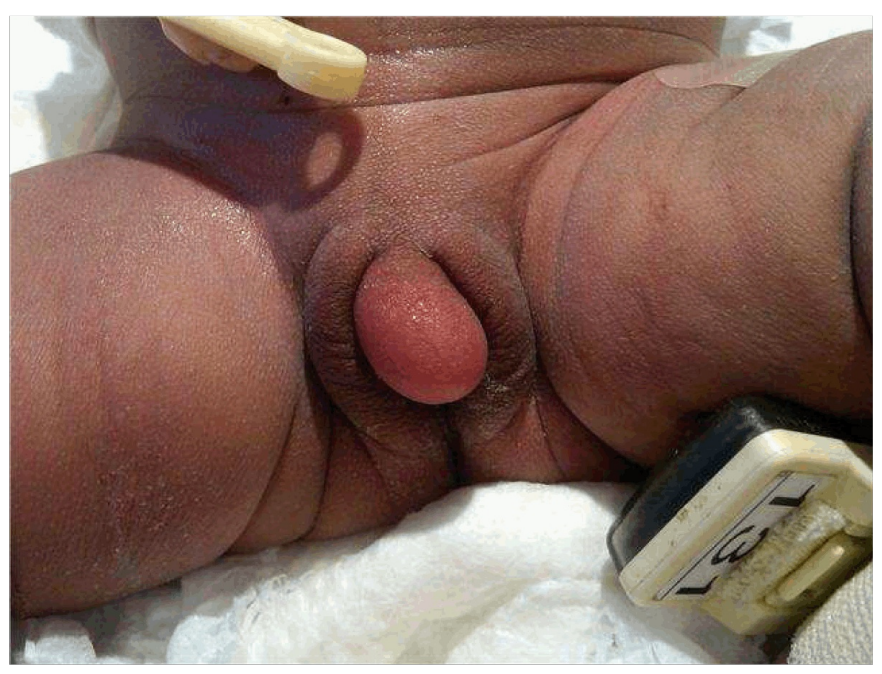

Figure 1: Patient's genitalia at initial presentation. 


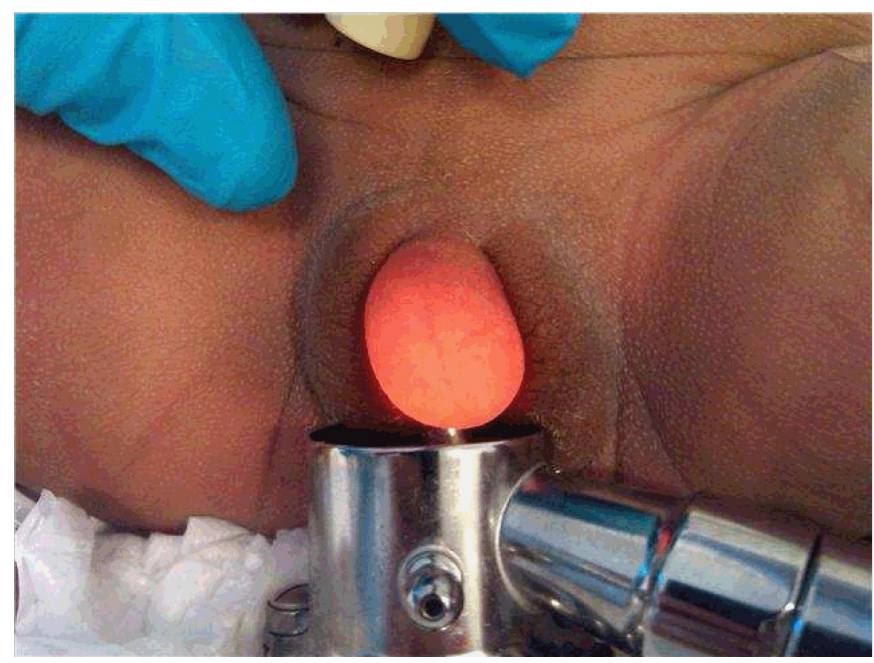

Figure 2: Patient's genitalia during physical examination.

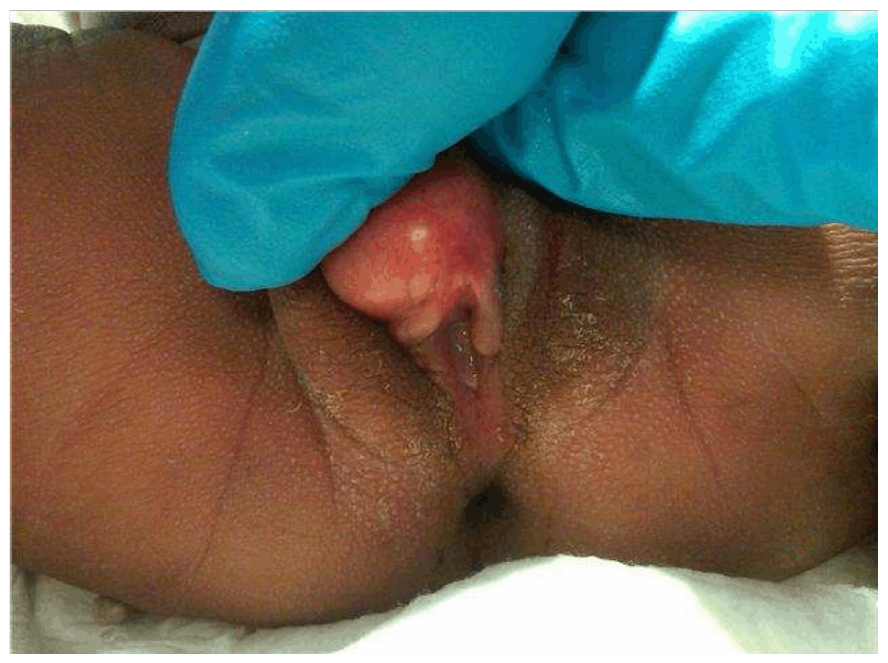

Figure 3: Patient's genitalia during the transillumination exam.

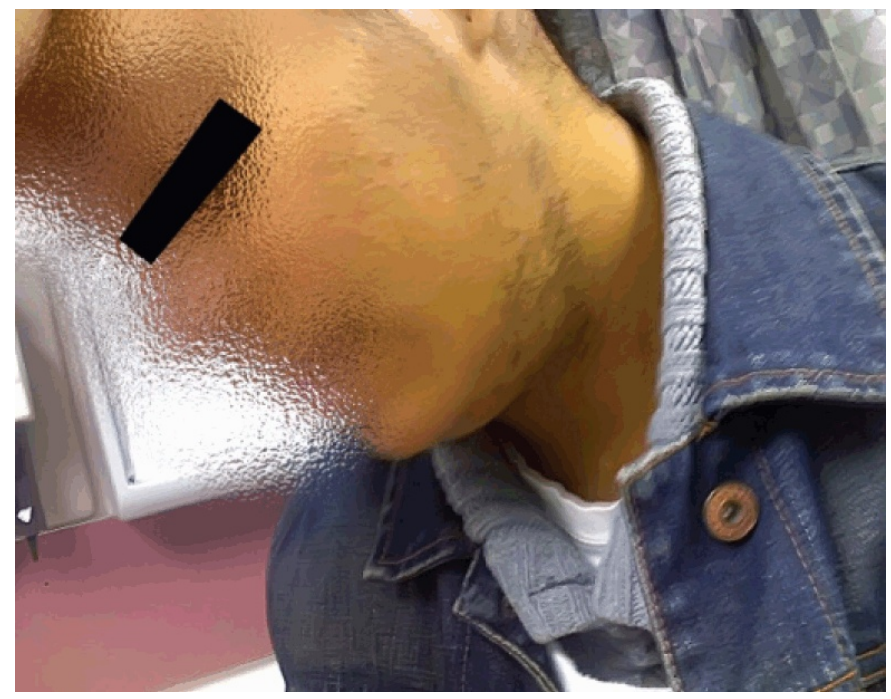

Figure 4: Appearance of the patient's mother.

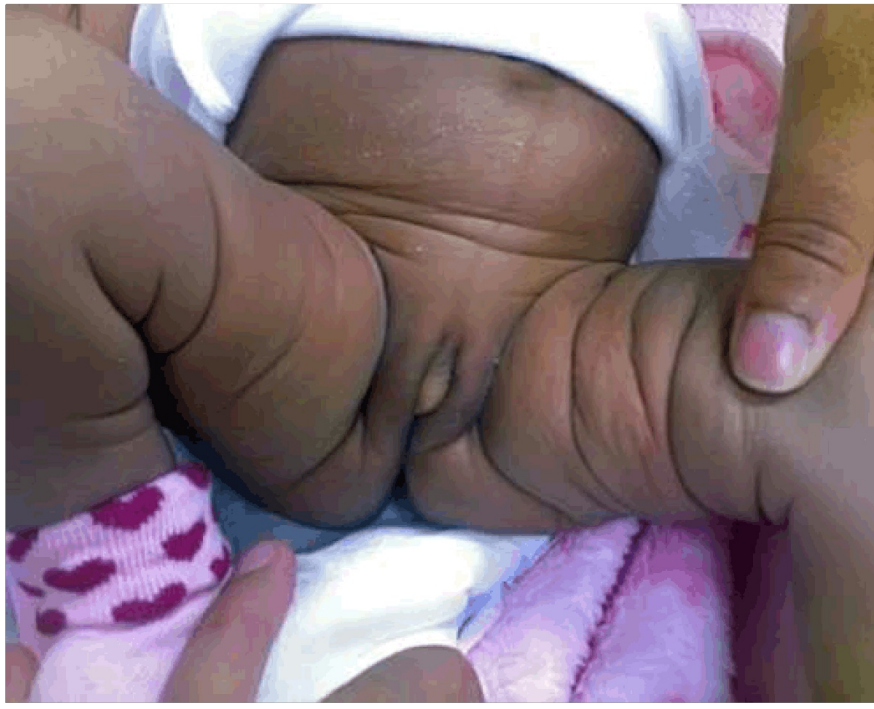

Figure 5: Patient's genitalia at two weeks of age.

\section{DISCUSSION}

Ambiguous genitalia is a disorder of sexual differentiation, where the external genitals do not have the typical appearance of either a boy or a girl. The genetic sex of a child is determined at conception. Normally, if a child inherits an $\mathrm{X}$ chromosome from both parents the genetic sex will be female, and if a child inherits one $\mathrm{X}$ chromosome from the mother and a Y from the father, the genetic sex will be male. The development of internal and external genitalia depends on the interplay of several hormonal stimulations or lack of stimulation during intrauterine life. If the process that causes this fetal tissue to become "male" or "female" is disrupted, ambiguous genitalia can develop. This genitalia makes it difficult to classify the infant as male or female.

Usually, ambiguous genitalia in genetic females (XX) may show an enlarged clitoris that looks like a small penis. The urethral opening can be along, above, or below the surface of the clitoris. The labia may look like a scrotum due to rugosity and hyperpigmentation. Depending on the degree of virilization, a female infant may look like a female with an enlarged clitoris or a fully virilized male with an urethra opening at the tip of the phallus, giving a normal penile appearance but an absence of palpable gonads. Prader staging system is commonly used for staging the virilization in females. Stage I: clitoromegaly without labial fusion, Stage II: clitoromegaly and posterior labial fusion, Stage III: greater degree of clitoromegaly, single perineal urogenital orifice, and almost complete labial fusion, Stage IV: increasingly phallic clitoris, urethra-like urogenital sinus at base of clitoris, and complete labial fusion, Stage V: penile clitoris, urethral meatus at tip of phallus and scrotum-like labia (appear like males without palpable gonads) [6]. Ambiguous genitalia in a genetic male (XY) may present from completely femalelooking genitalia to under-virilized male genitalia. 
Causes of ambiguous genitalia in a genetic female are related to an endogenous or exogenous excess of androgens during intrauterine life. Congenital adrenal hyperplasia is an autosomal recessive condition, a family of monogenic inherited disorders of adrenal steroidogenesis most often caused by enzyme 21hydroxylase deficiency (21-OHD). In the classic forms of $\mathrm{CAH}$ (simple virilizing and salt wasting), androgen excess causes external genital ambiguity in newborn females and progressive postnatal virilization in males and females [4]. Patients in some cases are exposed to male hormones prenatally either due to chemicals or maternal conditions such as androgen producing tumors causing androgenization of internal and external genitalia. Maternal hyperandrogenemia can be due to ovarian tumors, polycystic ovarian syndrome (PCOS) and a luteoma of pregnancy in rare cases [7]. Ambiguous genitalia is a true neonatal emergency and other pediatric specialties like genetics, urology and endocrinology need to be involved. Congenital adrenal hyperplasia should always be considered and ruled out. Sex should not be assigned until chromosomal results are confirmed.

A luteoma of pregnancy is usually unsuspected clinically and identified incidentally during a cesarean section or tubal ligation in the puerperium. It is a benign tumor that produces androgens and usually regresses postpartum spontaneously [7]. We suspect that the hyperandrogenemia causing hirsuitism in the mother and virilization in the female newborn was most likely due to a luteoma of pregnancy. The mother denies previous history of any drug that can potentially alter the sex hormones. Her ultrasound of the ovaries and hormonal workup was not conclusive for PCOS. Her testosterone levels were significantly higher than normal at the time of labor and regressed eventually in the first few months postpartum spontaneously without any intervention.

Embryologically, Bartholin's glands are outgrowths of the urogenital sinus, homologous to the bulbourethral glands in the male. The urogenital sinus comes from the cloaca and develops into the bladder, urethral glands, paraurethral glands, vagina, vestibular glands, Bartholin's glands, and hymen [3]. The function of these glands is to secrete mucus to lubricate the vagina. Anatomically, Bartholin's glands (greater vestibular glands) are homologues of the Cowper's glands (bulbourethral glands) in males. At puberty, these glands begin to function, providing moisture for the vestibule. The Bartholin's glands develop from buds in the epithelium of the posterior area of the vestibule. The glands are located bilaterally at the base of the labia minora and drain through 2-2.5 cm long ducts that empty into the vestibule. The glands are usually the size of a pea and rarely exceed $1 \mathrm{~cm}$. They are not palpable except in the presence of disease or infection. Obstruction of the distal Bartholin's duct may result in the retention of secretions, with resultant dilation of the duct and formation of a cyst. The cause of ductal obstruction is not known; however, it may have occurred secondary to the enlargement caused by the stimulation of sex hormones as was speculated in this case. The cyst may become infected, and an abscess may develop in the gland. The treatment of a Bartholin's duct cyst depends on the patient's symptoms. An asymptomatic cyst may require no treatment, but symptomatic Bartholin's duct cysts and gland abscesses require drainage. Unless spontaneous rupture occurs, an abscess rarely resolves on its own $[8,9]$.

\section{CONCLUSION}

In our patient, a Bartholin's cyst was responsible for the presentation of ambiguous genitalia in a newborn girl with hyperandrogenemia. The patient's hyperandrogenemia was secondary to maternal hyperandrogenemia. Ambiguous genitalia must always be considered a medical and psycho-social emergency. A multi-disciplinary approach is necessary for diagnosis and management. A simple bedside test, such as a transillumination test, can help decrease the latency in diagnosis.

$* * * * * * * * *$

\section{Author Contributions}

Swati Dave-Sharma - Conception and design, Acquisition of data, Analysis and interpretation of data, Drafting the article, Critical revision of the article, Final approval of the version to be published Christian Castillo - Conception and design, Acquisition of data, Analysis and interpretation of data, Drafting the article, Critical revision of the article, Final approval of the version to be published

Yolanda Cosme - Conception and design, Acquisition of data, Analysis and interpretation of data, Drafting the article, Critical revision of the article, Final approval of the version to be published

Evelyn Erickson - Acquisition of data, Analysis and interpretation of data, Drafting the article, Critical revision of the article, Final approval of the version to be published

\section{Guarantor}

The corresponding author is the guarantor of submission.

\section{Conflict of Interest}

Authors declare no conflict of interest.

\section{Copyright}

(C) Swati Dave-Sharma et al. 2012; This article is distributed under the terms of Creative Commons attribution 3.0 License which permits unrestricted use, distribution and reproduction in any means provided the original authors and original publisher are properly credited. (Please see www.ijcasereportsandimages.com /copyright-policy.php for more information.) 


\section{REFERENCES}

1. Sherif El Kady, Ahmed Al Zahrani, Roman Jednak, Mohamed El Sherbiny. Bartholin's gland abscess in a neonate: a case report. Can Urol Assoc J 2007 June;1(2):117-9.

2. Carolyn Chi, Henry Chong Lee and E. Kirk Neely. Ambiguous Genitalia in the Newborn. NeoReviews 2008;9;e78-84.

3. Jacob Estes, Sejal Dharia. Pathophysiology of ambiguous genitalia. OBGYN Knowledge Bank 2005 .

4. New MI, Carlson A, Obeid J, et al. Prenatal diagnosis for congenital adrenal hyperplasia in 532 pregnancies. J Clin Endocrinol Metab 2001 Dec;86(12):5651-7.

5. Rachel F Spitzer, Diane Wherrett, David Chitayat, et al. Maternal Luteoma of Pregnancy Presenting With
Virilization of the Female Infant. J Obstet Gynaecol Can 2007 Oct;29(10):835-40.

6. Prader A. Genital findings in the female pseudohermaphroditism of the congenital adrenogenital syndrome; morphology, frequency, development and heredity of the different genital forms [Article in German]. Helv Pediatr Acta 1954;9(3):231-48.

7. Heller DS, Frydman CP, Klein MJ, Bleiweiss IJ, Bacall C. Luteoma of pregnancy. Mt Sinai J Med 1990 Jan;57(1):40-2.

8. Omole F, Simmons BJ, Hacker Y. Management of Bartholin's duct cyst and gland abscess. Am Fam Physician 2003 Jul 1;68(1):135-40.

9. Jacob Estes, Sejal Dharia. Pathophysiology of ambiguous genitalia. OBGYN Knowledge Bank 2005 .
Access full text article on other devices

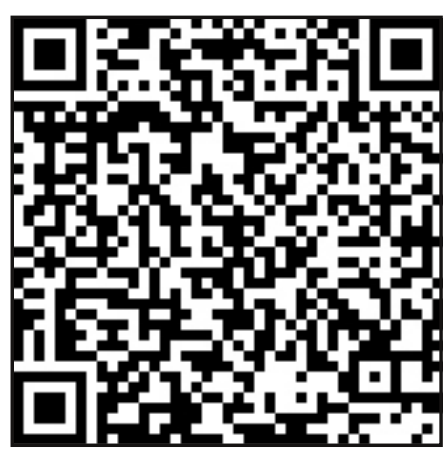

Access PDF of article on other devices

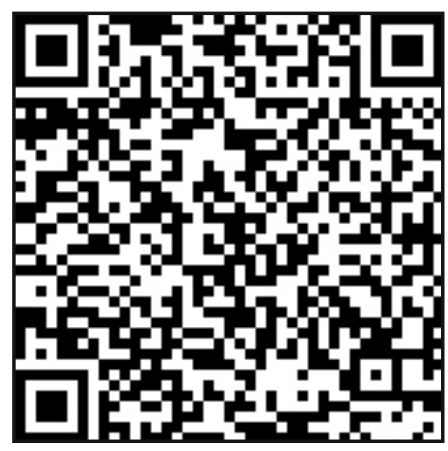

